\title{
O administrador público tipo delta para o século 21
}

Yehezkel Dror

\section{As tarefas de alta relevância dos governos centrais}

A estrutura e os funcionários de governos centrais devem ajustarse às suas principais tarefas. Algumas delas são claras e amplamente aceitas: fornecer segurança, gerir políticas macroeconômicas, desempenhar algumas funções regulatórias, fornecer determinados serviços sociais e facilitar o funcionamento dos processos da sociedade civil e do mercado econômico. Aumentar a eficiência e a eficácia do governo no cumprimento dessas tarefas é o enfoque central do "gerenciamento" e da "reinvenção do governo" (Osborne e Gaebler, 1992; Gore, 1993; MoOre, 1995; OCED, 1995), como também da "nova economia institucional", quando for aplicável (Williamson, 1996).

A maioria das reformas da administração e do serviço público são, no momento, dirigidas para a elevação do desempenho dessas tarefas governamentais, e isso inclui reformas radicais como a da Nova Zelândia (Boston et. al., 1991). Privatização, devolução, desregulamentação, corte nos gastos públicos e no emprego público, gestão responsável, utilização de métodos empresariais - essas são modalidades típicas de modernizar a nova gestão pública. Todos eles envolvem, além da remoção de muitas funções do governo central, o recrutamento de um novo tipo de funcionário público, o 'gerente público' (BЕKKE et al., 1996).

Estes são esforços, muitas vezes úteis e necessários. No entanto, eles sofrem de uma cegueira perigosa ao ignorar as funções de alta relevância realmente cruciais do governo, que são a tomada de decisões críticas e a adoção de políticas decisivas, que irão modelar o futuro de maneira

Yehezkel Dror é professor emérito de ciência política e professor catedrático de administração pública da Hebrew University of Jerusalem, Israel 
significativa (DroR, 1994-96: Cap. 6). Entre essas estão, por exemplo, projetos de infra-estrutura de larga escala; mudanças radicais na natureza do próprio estado, como a união das estruturas multiestatais internacionais; arquitetura da sociedade, como políticas sobre pobreza; governança do mercado; decisões sobre tecnologias emergentes; negociações envolvendo novos tipos de ameaças à segurança; adoção de posições com respeito a temas globais possivelmente catastróficos em escala global, como o efeito estufa; entre outros.

Se fizermos um exercício de raciocínio e perguntarmo-nos o que os futuros historiadores escreverão sobre a atual atuação dos governos, concluiremos que são esses os assuntos que receberão sua atenção. Os futuros historiadores irão avaliar nossa época como sendo uma era de transformações radicais, adequadamente chamada de a "primeira revolução global” (KING e ScHNEIDER, 1991), que ofereceu oportunidades e perigos sem precedentes (KIrdar, 1992; Kennedy, 1993; Kirdar e SiLK, 1994).

Os futuros historiadores também se lembrarão do lamento do clássico seguidor de Confúcio, Xunz, sobre uma pessoa defronte uma encruzilhada: "se um homem caminha meio passo na direção errada, quando ele perceber o erro, ele terá feito uma tolice de mil li” (KNOBLECK, 1990: 161). Minha previsão é de que, a menos que sejam aperfeiçoadas as capacidades essenciais do governo central de engajar-se nas tarefas de alta relevância, estabelecendo as trajetórias rumo ao futuro, os futuros historiadores acrescentarão lamentos amargos sobre o futuro que eles irão viver, culpando-nos do fracasso em ajustar o governo central às suas tarefas mais críticas, em grande parte em função da preocupação com a "nova gestão pública" (KöNIG, 1995).

\section{A necessidade de uma administração pública radicalmente nova}

Novas condições requerem novas formas de governança. Nossa época é, em muitos aspectos, cheia de novidades radicais. Existe, no entanto, a necessidade de um redesenho radical da governança e das políticas, com base numa "revolução conceitual" (BALL et al., 1988; THAGARD, 1992), para que sejam atingidas as necessárias habilidades para governar. Educar o público, capacitar políticos, forçar a aplicação de severos códigos de ética, desenvolver razões humanistas progressistas em substituição parcial das razões de estado, buscar novas formas de cooperação regional e fortalecer a governança global e o controle público sobre o poder privado global, tornando os governantes mais responsáveis junto às sociedades 
civis - são exemplos de algumas das direções nas quais a governança deve mudar, para adequar-se a uma época de saltos quantitativos e de mudanças de valores e expectativas (DROR, 1988, 1994-96).

Entre as mudanças necessárias à governança, uma transformação em busca de um novo tipo de administração pública é particularmente importante. O redesenho do serviço público é essencial para fornecer ao governo central o conhecimento e as perspectivas necessárias para o desempenho de tarefas ainda mais relevantes. Ao mesmo tempo, redesenhar a administração pública é relativamente menos difícil que, digamos, reduzir a ignorância de muitos políticos e torná-los mais virtuosos. Entretanto, dentro de uma estratégia modular de redesenho, começar com a administração pública é quase sempre a melhor decisão. Este artigo pretende traçar algumas recomendações para o desenvolvimento de um novo tipo de servidor público, preparado para o exercício das tarefas de alta relevância dos governos centrais, que eu passarei a chamar de "administrador público tipo delta".

Utilizando uma grosseira classificação histórico-comparativa, veremos que a administração pública tipo alfa, que predominou durante muitos períodos históricos, e que ainda pode ser encontrada em vários países, baseia-se num status atribuído, normalmente um direito de nascença ou proximidade pessoal com os governantes, com uma grande fusão dos papéis político e administrativo. $\mathrm{O}$ administrador público tipo beta surge principalmente pela compra de posições de governo, o que geralmente significa uma melhoria substancial tipo alfa, pois a posse de recursos, ou o nascimento em uma família rica, implica, pelo menos, algumas qualificações. A administração pública do tipo gama é baseada em um quase-profissionalismo. Seus antecedentes incluem escravos educados quase-profissionais e pessoas liberadas preenchendo funções de servidores públicos na Roma clássica e, na Idade Média, padres formados, como os jesuítas. Muito mais profissionais e baseados em mérito eram os sistemas clássicos dos mandarins na China, que levaram a versões modernas como a classe administrativa inglesa e a elite estatal francesa treinada pela ENA (École Nationale d'Administration). Muitos dos administradores públicos modernos pertencem ao tipo gama, com a nova administração pública constituindo um subtipo, onde as aptidões gerenciais como o treinamento em direito substituem outras exigências profissionais.

No entanto, quando avaliada em termos dos requerimentos para engajar-se nas tarefas de alta relevância dos governos centrais e nas novas disciplinas e modalidades de conhecimento, a administração pública tipo gama, em todas as suas variações, mostra-se inadequada. Vem daí a necessidade e o potencial de mudança por uma administração pública tipo delta, que reforça a atenção às tarefas de alta relevância, ao passo que deixa as tarefas gerenciais para oficiais graduados tipo gama e vários prestadores de serviço. 


\section{A realidade do administrador público contemporâneo}

A necessidade urgente de um tipo novo de administração pública é fortemente apoiada por uma avaliação da realidade e das tendências atuais. Um estudo extenso sobre os servidores públicos em um grande número de países levou-me, em todo caso, à conclusão de que quase todos os serviços públicos contemporâneos são obsoletos em aspectos vitais, estando aqueles recentemente reformados muito melhores para executar a administração pública, mas com conhecimentos praticamente irrelevantes para as tarefas mais relevantes dos governos centrais.

Em muitos países, a experiência profissional dos servidores públicos é inadequada, advinda da formação em Direito ou numa prática generalista; os incentivos à entrada na administração pública são, na maioria dos países, inadequados para atrair uma proporção significativa do melhor; a divisão imprópria de trabalho com políticos ameaça de maneira crescente as contribuições específicas esperadas de uma administração pública; o conhecimento dos administradores públicos é, muitas vezes, grosseiramente desatualizado; muitos países prendem-se a uma tradição de serviço público baseado em regras, o que torna o profissionalismo criativo impossível (para uma perspectiva histórica, ver SILBERMAN [1993]); a corrupção parece crescer, muitas vezes como um correlato à corrupção dos políticos; com freqüência, as reformas na administração pública realmente melhoram sua eficiência, mas são irrelevantes para os principais dilemas políticos; as poucas possibilidades de carreira para muitos funcionários públicos inibem uma perspectiva nacional global; a rotação é, em geral, excessivamente freqüente ou limitada, muitas vezes os dois casos; as culturas do serviço público são normalmente conservadoras, inibindo o desabrochar da inovação tão necessária; no nível global, as dificuldades políticas combinam com os interesses investidos, criando um serviço público internacional muito pouco qualificado, para não ser grosseiro, para suas responsabilidades crescentes.

Assim, cheguei à minha conclusão de que, com algumas variações, praticamente todo o serviço público contemporâneo está obsoleto, como algumas exceções localizadas, principalmente ao sul da Ásia Oriental. Há alguns estudos de caso disponíveis, que servem para ilustrar essa conclusão (ButLER et. al., 1994; BovENS e HART, 1996). Esta avaliação foi posteriormente reforçada pelos esforços de vários países em reformar seu serviço público (Boston et. al., HeAdy, 1995; BeKKe et at., 1996). A maioria das reformas mantêm-se dentro da estrutura clássica tipo gama, ou acrescentam a abordagem da nova gestão pública, ou adotam uma combinação dos dois anteriores, mas quase todas fazendo pouquíssima diferença na prática (BRUNSSON e OLSEN, 1993). Elas são geralmente úteis para avançar com eficiência e eficácia e, em países como os da Europa 
Oriental, são essenciais para a construção das capacidades essenciais do governo (SIGMA, 1995). Mas elas não apresentam significativas contribuições às outras tarefas relevantes dos governos centrais, e muitas vezes trazem risco por distraírem a atenção deles da necessidade de atualização. Isso é muito bem ilustrado pela Nova Zelândia, que tem a mais avançada das reformas da administração pública, com muitas conquistas em termos de eficiência e eficácia, mas nenhuma com respeito à capacidade crítica de escolha do governo central.

As ideologias e estruturas contemporâneas adicionais dificultam uma consideração mais séria sobre a necessidade de um novo tipo de administração pública. Elas incluem, por exemplo, uma redução generalizada da importância dos governos, combinada com desconfiança, crenças populistas antielitistas, políticos de mídia, nada dispostos a serem forçados ao conhecimento profissional, preocupação com os cortes nos gastos públicos e privatização, e muito mais.

Sem muita surpresa, a necessidade de um novo tipo de administração pública é ignorada (nem seriamente considerada nem rejeitada!) em quase todo o discurso sobre administração pública e reforma de governo (Wamsley et al., 1990; Kaufmann, 1991; McDonanld, 1992; Gore, 1993). No entanto, a inabilidade sempre visível dos governos de adaptar-se à pressão dos problemas, junto à frustração das esperanças fixas aos mercados como soluções universais irão, com certeza, revigorar a busca por novos desenhos de governança inovativa. Possuir idéias adequadas para o momento da grande oportunidade é uma tarefa para pensadores profissionais dedicados à governança onde, com sorte, o modelo tipo delta aqui proposto estimulará a real inventividade no governo, que será seguramente exigida no futuro próximo.

\section{Capacidades essenciais da administração pública tipo delta}

Um breve exame das principais funções da administração pública tipo delta servirá como ponte entre a necessidade generalizada por um redesenho do governo e a discussão sobre as características principais do servidor público tipo delta.

Para ajustar-se aos novos desafios, oportunidades e perigos e estabelecer trajetórias rumo ao futuro, ao mesmo tempo em que cumprem suas tarefas de alta relevância, os governos deverão, inter alia, engajarse em sete funções principais, por vezes sobrepostas:

1. Intervenção em processos históricos, para reduzir a probabilidade do mal e aumentar a possibilidade do bem, visto que isso muda com o tempo; 
2. Potencialização, no sentido de apoiar e impelir, dos processos sociais criativos e evolutivos (e não o "desenvolvimento auto-sustentável", com todas as suas conotações estáticas), ultrapassando o significado do jargão 'facilitar';

3. Ativa arquitetura da sociedade, guiando e também ajustando diretamente as principais estruturas e processos sociais rumo a condições e valores radicalmente diferentes, incluindo a necessária destruição criativa (SCHUMPETER, 1942: cap.7), quando os processos sociais autônomos mostrarem-se inadequados;

4. 'Jogo político', para fazer escolhas críticas que irão modelar o futuro, tendo em vista as incertezas e possibilidades inconcebíveis do momento, que transcendem o pensamento probabilístico;

5. Habilidade em lidar com complexidades crescentes, além da compreensão disponível;

6. Escolha trágica entre as prioridades e os valores em debate ambíguos e em constante mudança; e

7. Mobilização do apoio para a dolorosa destruição construtiva, inevitável mesmo sob as melhores condições.

Outras classificações das funções principais envolvidas nas tarefas relevantes dos governos centrais são possíveis, mas não afetarão a conclusão principal de que os governos contemporâneos não possuem as capacidades absolutamente essenciais para preencherem as funções envolvidas com suas tarefas relevantes. De fato, uma crítica ainda mais severa se justifica: as funções necessárias podem muito bem estar além do potencial máximo dos caminhos (NORTH, 1990) oferecidos pelas estruturas governamentais do momento.

Assim, como afirmado anteriormente, o redesenho radical da governança é essencial. Deixando de lado outros requisitos, tais como a elevação das qualidades cognitivas e morais dos políticos e a sofisticação do cidadão comum, um dos novos componentes essenciais exigido das mentes de um governo central é um stratum profissional de altíssima qualidade. Esse stratum pode oferecer um máximo de compreensão e conhecimento profissional, junto a uma visão ampla e perspectivas bastante amplas. Além do mais, para realizar sua contribuição mais crucial, esse stratum deve gozar de plena autonomia dos componentes políticos do governo, de acordo com as versões sofisticadas de democracia como um regime misto, que possui instituições de governo não-democráticas, como as cortes e os bancos centrais, juntamente com serviços públicos que cumprem funções importantíssimas, enquanto obedecem e seguem valores democráticos, sendo subordinados, em última instância, aos políticos eleitos.

$\mathrm{O}$ administrador público tipo delta, com atributos que o capacitam a cumprir o papel principal de corresponder às funções envolvidas com as tarefas mais relevantes dos governos, está projetado para atuar como esse stratum. 


\section{Atributos tipo delta}

Para corresponder às suas funções, o administrador público tipo delta difere de seus predecessores (alfa, beta e gama) nas principais qualidades. Ele continua a linha de desenvolvimento de alfa para beta e para gama até delta em termos da sua crescente profissionalização. Mas o tipo delta aqui proposto busca um salto qualitativo, comparável ao que costuma chamar-se a revolução governamental do século 19 (MACDonAGH, 1958).

As principais características do administrador público tipo delta incluem uma concentração de aptidões de alta relevância: superprofissionalismo; inovativo-criativo; meritocrático-elitista, porém refletindo a sociedade; virtuoso; autônomo, porém subordinado; e um forte sentido de missão. Um breve exame desses atributos servirá para apresentar o conceito de um administrador público tipo delta em um nível de detalhes suficiente para servir de base para o pensamento futuro e para ação.

\subsection{Concentração de aptidões de alta relevância}

Muito da energia e da atenção do administrador público vai para a minigestão. Isto não só significa o desperdício de um recurso muito escasso, mas também garante que as escolhas e atividades mais importantes, aquelas que realmente farão diferença, estão sendo negligenciadas. Este é um defeito seriíssimo, ainda mais visto que políticos em vários países têm-se desviado crescentemente daquilo que realmente faz diferença, por pressão de demandas da mídia e dos rituais modernos e eleitoreiros.

Assim, o atributo principal do administrador público tipo delta seria $a$ atenção às escolhas críticas e às ações com alta probabilidade de impacto no futuro coletivo. Aqui, novamente, muito dependerá de arranjos institucionais. Assim, para chamar a atenção das mentes dos governos centrais àquilo que realmente importa, será preciso transferir algumas tarefas para o mercado, ONGs, sindicatos, movimentos de base e esferas inferiores de governo, ou seja, para qualquer organização que possa cumprir bem essas tarefas, e as outras obrigações administrativas deveriam ser delegadas a administradores públicos.

No entanto, essa transferência de funções não será adequadamente implementada, nem produzirá os resultados desejados, a menos que os administradores públicos desejem ocupar-se daquilo que realmente interessa, e sintam-se relativamente competentes para concentrar-se nas funções de alta relevância do governo central.

O modelo da administração pública tipo delta não é utópico. Ele admite que o envolvimento excessivo com a minigestão e com os incêndios habituais é inevitável. É isso que a capacidade de resposta exige, é isso que os políticos geralmente esperam, e é isso que o poder oferece. Assim, não 
é a falta de envolvimento com a minigestão e com as microcrises que caracteriza o administrador público tipo delta, mas a limitação desse envolvimento em, digamos, no máximo $50 \%$ do tempo, atenção e energia. Isso deixa $50 \%$ da capacidade livre para as tarefas mais relevantes do governo - fato que significa uma grande mutação, se comparado com a realidade presente.

A concentração em tarefas de alta relevância e em outras funções relativas a elas não é uma mera questão de alocação de recursos; ela também exige rotinas pouco usuais de trabalho, que incluem muita leitura, retiros, contemplação política, contato com pensadores e cientistas e muito mais. Basicamente, é preciso uma nova cultura de administração pública, que busque fazer diferença no futuro. Outro assunto relacionado a isso é a necessidade de manter-se autonomia vis-à-vis aos políticos, como já discutido. No entanto, as bases principais para se alcançar essas características são capacitação, qualificação e identidade profissionais, que motivem, capacitem e apóiem a concentração nas tarefas realmente relevantes. Assim, a essência da administração pública tipo delta está no seu superprofissionalismo.

\subsection{Superprofissionalismo}

A característica mais importante do administrador público tipo delta aqui proposto é seu altíssimo nível de profissionalização, muito mais do que o tipo gama. Considerando que tornar-se um médico toma pelo menos sete anos de estudos intensivos e outros três para especialização, é um tanto estranho que os profissionais do governo não tenham de enfrentar um curso pelo menos tão longo de estudos e aprendizado clínico. Se os estudos modernos que demonstram a extensão de tempo necessária para tornar-se um especialista forem considerados (ERICSSON e SMITH, 1991), junto à rápida expansão do conhecimento relevante para o exercício do governo, chego à conclusão de que os administradores públicos deveriam ser superprofissionais, com estudos equivalentes, pelo menos, à especialização médica, e constantemente envolvidos com aprendizados suplementares, intercalando períodos de estudo e de experiência variada.

A essência do profissionalismo (Dror, 1993) é a prática baseada no vasto conhecimento (ScHON, 1983), como também a inteligência prática advinda da experiência (Sternberg e Wagner, 1986). Somem-se a elas uma atitude de preocupação clínica e a capacidade de ser frio no meio da irracionalidade emocional e em uma arena altamente competitiva; uma boa dose de ceticismo, com fortes suspeitas do óbvio, beirando a iconoclastia e o aprendizado constante.

Tomando como certas exigências mínimas e amplamente reconhecidas, tais como habilidades em linguagem e no uso de computadores, e o 
conhecimento de assuntos como direito público, deixe-me indicar alguns grupos de conhecimento e aptidões necessárias, que vão além do tipo gama e que significam um avanço rumo ao superprofissionalismo. Pessoas diferentes satisfariam mais a um grupo de exigências e menos a outro. Porém, todos os administradores públicos tipo delta deverão atingir um bom nível em todos eles, elevando a administração pública como um todo a um patamar de excelência em todos os domínios.

- Eles deverão possuir uma profunda compreensão dos processos sociais em todas as suas dimensões, incluindo suas bases psicológicas.

- Deverão ponderar sobre o estabelecimento de trajetórias rumo à história futura. Isso envolve muito pensamento histórico, aplicação de especulações e conjecturas na ascensão e declínio das nações, avaliação de perfis sociais em termos de potencial evolutivo, muita contemplação de alternativas futuras e a construção de visões múltiplas da realidade.

- Instituições e suas dinâmicas, tanto como empecilhos quanto objetos de arquitetura social, devem ser compreendidas.

- Os principais meios e suas dinâmicas, incluindo o próprio meio social e seu meio-ambiente, até a globalização, devem ser profundamente estudados.

— Habilidade com números (PAUlos, 1988) é uma necessidade premente como uma linguagem para a compreensão, reflexão e raciocínio. No entanto, o raciocínio em linguagem numérica, como por exemplo, nas principais formas de incerteza (KAPLAN, 1996) deve ser combinado não só com o pensamento histórico, mas também com a imaginação literária (NuSSBAUM, 1994). Essas exigências aparentemente contraditórias ilustram bem a multidimensionalidade do superprofissionalismo tipo delta, e levam à necessidade inerente do pensamento dialético (Mitroff et al., 1983), com base na filosofia de ação e julgamento, filosofia da mente e das ciências cognitivas modernas (Elster, 1983, 1984, 1989; BrATMAN, 1987; GrAHAM, 1993).

- Devem conhecer profundamente a literatura científica e tecnológica, incluindo as implicações e temas sociais, como aqueles levantados pela tecnologia da informação, pela robótica, biotecnologia, etc.

- Deve haver familiaridade com os principais temas políticos, com ênfase na coerência e perspectiva dinâmica ampla.

- Deve haver conhecimento da realidade da tomada de decisão e também dos modelos normativos, no nível das estruturas individuais, organizacionais, governamentais, sociais e globais.

- Qualificações avançadas nos princípios e métodos do policymaking, muito além do padrão da análise política, são necessárias; em particular, os quadros mais relevantes da esfera estatal de pensamento político, tais como as perspectivas dinâmicas dos sistemas e da aposta na história; familiaridade com as ferramentas e técnicas mais proeminentes, tais como simulação e jogos, traço de perfis psicológicos e mapeamento 
incerto. Mais importante e mais difícil de alcançar será o conhecimento

explícito das abordagens da ponderação política avançada, que levará, no final, a hábitos cognitivos de pensamento e intuição.

— Uma boa medida de valor filosófico e raciocínio ético é básica para o conhecimento e aptidão necessários, para explorar a dimensão decisiva de valores das principais escolhas públicas e análise das escolhas trágicas, de forma a ajudar as decisões tomadas pelos juízes de valor legítimos — os políticos. Boa familiaridade com filosofia política clássica e moderna é uma exigência concomitante.

- Todos esses requerimentos devem ser colocados em estruturas regionais e globais, até que se atinja um nível de raciocínio em termos do que eu costumo chamar raison d'humanité (DroR, 1994-96; cap. 9).

- Além da reconhecida necessidade de conhecimento e habilidade para gerenciamento, teoria organizacional e psicologia organizacional, administração pública comparada, matérias especiais como gerenciamento de projetos em larga escala e uma boa dose de habilidade para a reforma - todas voltadas para níveis macro — são também necessárias.

- Conhecimento de finanças públicas e orçamento e de gestão de recursos também devem ultrapassar o que usualmente se exige do modelo tipo gama. Assim, o custo da meta nacional, abordagens da agenda pública e o estabelecimento de prioridades e de métodos orçamentários para vários anos também são necessários. Para todos esses requerimentos gerais, o conhecimento particular de domínios específicos das atividades de governo, como saúde, assuntos econômicos e industriais, segurança nacional, entre outros, deve ser adicionado. Isso exige certo aperfeiçoamento do administrador público tipo delta, com especialização em domínios específicos. No entanto, para se assegurar uma perspectiva ampla, todo administrador público tipo delta deve ter conhecimento específico e experiência em, pelo menos, dois domínios das atividades governamentais.

As habilidades são tão difíceis de definir quanto as exigências de conhecimento. Elas envolvem, em parte, a absorção de conhecimentos pelo comportamento intuitivo e pensamento espontâneo. Isso requer aprendizado ativo e contínuo, combinado com um ensino apropriado, planejamento de carreira e aconselhamento profissional. Algumas aptidões necessárias estão relacionadas ao caráter, como o pensamento frio e rápido em situações de crise. Isso é, em parte, uma questão de talento e propensão inatos, que serão identificados pela avaliação do desempenho de toda a carreira, e que deverão ser promovidos com ajuda de experiências estruturadas e métodos especiais de treinamento, tais como exercícios de crise.

$\mathrm{O}$ administrador público tipo delta precisa ainda de aptidões padronizadas, como as exigidas nos relacionamentos humanos e negociações. 
No entanto, a principal aptidão, que caracteriza o profissionalismo do administrador público tipo delta, é a habilidade e o hábito de construir a ponte entre o conhecimento abstrato e temas concretos, de forma explícita e tácita. Tudo isso, somado ao julgamento, é baseado numa combinação de conhecimento e experiência.

Há ainda uma dimensão adicional para a característica superprofissional do administrador público tipo delta — a combinação de contemplação e ação. É impossível pensar através de situações inusitadas mutantes e compreender problemas fundamentais com o ritmo frenético dos níveis mais altos do governo. Para ir além das aparências superficiais até processos mais profundos, o tempo para refletir fora da pressão dos eventos presentes é essencial. Assim, administradores públicos tipo delta devem dedicar-se a muita contemplação direcionada para a ação, e dispor de tempo e condições para fazê-lo. Essencialmente, estou aplicando novamente o modelo aristotélico da filosofia como um guia de ação (NuSSBAUM, 1990: cap.2), com os administradores públicos tipo delta sendo, em parte, filósofos da ação política e de governo.

\subsection{Inovativo-criativo}

Inovação e criatividade são essenciais para a adaptação a novos temas e situações, quando o "mais do mesmo" e o "incrementalismo" tornam-se não só inúteis, mas contraprodutivos. No entanto, ser inovativocriativo não é menos importante para o tipo delta do que o superprofissionalismo - ambos devem combinar-se.

A busca pela inovação e criatividade coloca alguns problemas. $\mathrm{Pa}-$ rece, pelo pouco que se sabe desse tema enganoso, que criatividade pessoal significativa é uma capacidade escassa, em grande parte, um resultado da personalidade e, portanto, não pode ser ensinada. E ainda pior, muitas estruturas e processos organizacionais e governamentais são, na prática,de natureza antiinovadora.

É possível desenhar estruturas e processos organizacionais que encoragem a inovação e a criatividade (MERritT e MERritT, 1985; Schaefer e McInemey, 1988; Senge, 1990), mas aqui me interesso nas medidas para aumentar a inovação e criatividade como parte da proposta para uma administração pública tipo delta. Assim, os comentários que se seguem são relevantes.

- Um serviço que combine carreira pessoal e recrutamento aberto deve estimular mais a inovação e a criatividade, sem desfigurar seu caráter compacto e superprofissional. Cerca de $50 \%$ dos quadros da administração pública tipo delta deveriam ser compostos por funcionários de carreira, com entrada num nível inicial do recrutamento, e pelo menos $25 \%$ das posições a serem preenchidas por recrutamento aberto, sendo o recrutamento dos $25 \%$ restantes mais elástico. 
- A juventude parece aumentar a inovação. Assim, a administração pública tipo delta deveria ser mantida, em grande parte, jovem, com profissionais muito destacados que rapidamente atingissem as posições mais elevadas.

- Tempo para aprender, contemplar e procurar novas idéias é essencial para a criatividade. Assim, as carreiras deveriam incluir, como mencionado anteriormente, retiros periódicos e períodos de contemplação, longe das pressões e atividades diárias.

— Exposições variadas estimulam a inovação e criatividade. Fazse necessária uma carreira que forneça experiências múltiplas e interface com realidades heterogêneas.

É inútil recomendar que a inovação e a criatividade sejam um dos principais critérios para a entrada na administração pública tipo delta, visto que essas características não podem ser identificadas com segurança antes de serem colocadas à prova por anos de serviço, mas a curiosidade pode ser avaliada e deve constituir uma exigência principal. Além disso, como a inovação e a criatividade freqüentemente caminham junto às idiossincrasias, o recrutamento deve evitar a eliminação de tais pessoas em função da ênfase excessiva em aptidões para trabalho em grupo, etc., e até dar boas-vindas a uma boa medida de tipos incomuns. Isto também se aplica à promoção, com especial atenção à inovação e à criatividade, mesmo quando isto implicar imposições em termos de hábitos harmoniosos de trabalho e relações humanas.

\subsection{Meritocrático-elitista, porém refletindo a sociedade}

A administração pública tipo delta é abertamente meritocráticoelitista ao tentar atrair, selecionar e desenvolver o melhor, num sentido múltiplo. Ela requer, inter alia, o alargamento da base através de recrutamento e promoção de mulheres e de vários grupos étnicos, tornando-se atraente em termos de desafios, e competitiva em termos de remuneração, possuindo um sistema de seleção e carreira que escolha e mantenha o melhor, enquanto filtra os "não-tão-melhores" e aposenta aqueles que perdem seu caráter mais agressivo. Assim, o vínculo profissional permanente deve ser evitado, com os oficiais trabalhando com contratos de cinco ou 10 anos, renováveis com base no mérito, segundo avaliação realizada por órgãos independentes. Os pagamentos, incluindo os fundos de pensão, devem ser ajustados de forma a compensar essa falta de estabilidade, e compensar as pessoas cujos contratos não sejam renovados em virtude da diminuição da inovação, mas não por falha pessoal.

A alta qualidade da administração pública tipo delta deve ser combinada com seu caráter compacto. Muitos países necessitam de uma administração pública tipo delta formada por não mais de, digamos, 500 pessoas 
(e muito menos em estados pequenos), podendo alcançar até $2.500 \mathrm{em}$ países de extensão continental como China e Índia. Qualidade altíssima e pequena quantidade combinam-se para transformar a administração pública numa elite meritocrática compacta, porém pluralista, com sentido de corporativismo (esprit de corps) e de missão.

A administração pública tipo delta é meritocrática. Nenhum outro princípio, como por exemplo, antigüidade em partidos políticos, não deveria ter influência: só o mérito em qualidades e concretizações. Este é um princípio fundamental que nunca deve ser comprometido.

No entanto, a administração pública tipo delta deve também ser pluralística, em termos de gênero, etnia, antecedentes socioeconômicos, visão mundial, etc. Tal pluralismo é necessário para refletir a sociedade e manter-se próximo a ela; para ajustar-se aos requerimentos das diferentes tarefas; para fornecer perspectivas múltiplas, essenciais ao ajustamento, à complexidade; e para estimular a inovação e a criatividade.

Medidas especiais seriam necessárias para que fosse atingido um espelhamento adequado da sociedade, incluindo oportunidades de treinamento intenso e incentivos para grupos pouco representados, como também algumas medidas discriminatórias positivas, enquanto seu principal conhecimento e exigência de aptidões não forem depreciados.

A administração pública tipo delta, enquanto elitista, deve não só espelhar a sociedade, mas também estar próxima a ela — para corresponder aos seus valores e, igualmente importante, para compreender as múltiplas realidades sociais essenciais para o desempenho de suas funções. Esta é a exigência mais importante, visto que muitas das características elitistas da administração pública tipo delta carrega com ela os graves perigos de perder contato com as realidades sociais. Assim, a administração pública tipo delta abriga membros que trazem a experiência e o conhecimento de diferentes estilos de vida e de experiência existencial, ou que adquirem tal experiência e conhecimento após sua entrada na administração pública. As carreiras deveriam também incluir um período de, pelo menos, um ano de trabalho com organizações e movimentos de base.

\subsection{Virtuoso}

Com a desmistificação do estado e o movimento contrário ao status do contrato, as exigências éticas dos servidores públicos foram reduzidas em muitos países. As mudanças em culturas dominantes — da ética pública para a comercial (JACOBS, 1992) — agravaram ainda mais a erosão da ética das administrações públicas. Atualmente, as exigências da administração pública tipo gama são geralmente limitadas à prevenção da corrupção, à redução do conflito de interesses e, em alguns países, à proibição da greve. A realidade é ainda pior, com crescentes sinais de 
corrupção, com greves violentas e ligadas a grupos de interesse, tornando-se endêmicas em um número crescente de serviços públicos.

Por vezes, alguns passos são dados em direção às normas éticas do serviço público (Williams et al., 1985; Thomas, 1993). Mas, como um todo, o assunto tem sido negligenciado. Ao resistir a essa realidade perigosa, o administrador público tipo delta distingue-se pelas demandas sérias com respeito a ética, valores e virtudes.

Um primeiro conjunto de padrões mínimos exige compromisso total com a res publica, onde o conflito de interesses é seriamente evitado, e a publicidade evitada a todo custo. Valores que equilibram compromisso com a vontade pública e obediência a superiores políticos e administrativos, incluindo normas de quando sair e encerrar a partida, são também essenciais (HIRSCHMAN, 1970; também reconsiderado por Hirschman, 1986: cap. 4).

Mas neste caso exige-se muito mais, como a reintrodução das noções de virtudes e vícios, e também do caráter, aplicando-se os interesses modernos a esses conceitos (GuARdini, 1967; WALlAnCE, 1978; MACKInTYRE, 1984; KUPPERMAN, 1991) para a elite da administração pública.

Uma fonte importante para a concepção ética apropriada do serviço público tipo delta é a clássica ética de Confúcio (Wright e TwichetT, 1962; Hall e AMEs, 1987; WALEY, 1988). Importantes ajustes às condições modernas são necessários (BARY, 1991), incluindo a ênfase à inovação, criatividade e ação enérgica, mas, considerando-se todos os fatores, a ética de Confúcio modernizada é uma boa base para a construção de uma ética pessoal e profissional das virtudes da administração pública tipo delta.

Servidores públicos devem também, e basicamente, comprometer-se com os valores mais prementes, incluindo os humanos, sociais e nacionais. No entanto, podem haver respostas diferentes para a questão de quanta identificação pessoal com as ideologias dominantes aceitas em uma sociedade particular, em um certo período de tempo, deveria ser exigida dos administradores públicos tipo delta. Está claro que, em países democráticos, a identificação com os valores democráticos é uma exigência. Da mesma forma, a identificação com o desenvolvimento como valor e como meta nacional é exigida em países em desenvolvimento. Mas o tema torna-se difícil, quando diz respeito a sistemas políticos ou de crença religiosa nas sociedades não liberaldemocráticas.

Eu penso que nesses países, a identificação (em contraste com a cegueira dogmática) com valores dominantes pode bem ser exigida dos administradores públicos . No entanto, isto não deve sobrepor-se à obrigação fundamental do ser humano de rejeitar e resistir ao mal. Como identificar o mal e quando resistir à ideologia dominante por causa do 
ser humano superior e de outros valores - estas são questões de res-

ponsabilidade moral pessoal, para a qual nenhuma resposta genérica pode ser fornecida.

\subsection{Autônomo, porém subordinado}

Na base desse atributo crucial está a concepção genérica da administração pública tipo delta como um stratum não-democrático, essencial, mesmo no mais democrático dos países, para o cuidado do interesse público, que é cada vez maior. No entanto, esta é uma matéria difícil, com problemas complexos como o equilíbrio entre autonomia e subordinação, conforme expressam algumas características.

O administrador público tipo delta deve ser autônomo em seu trabalho profissional e muito influente nas tomadas de decisão, mas está, obviamente, subordinado a superiores políticos, visto que está profissionalmente obrigado a 'dizer a verdade ao poder' (WILDAVSKY, 1979), a confrontarse com escolhas políticas ruins e, se necessário sair e encerrar a partida.

A necessidade de saber como mobilizar e manejar o poder, e paralelamente respeitar as políticas e servir às metas legítimas é também uma necessidade. Ao mesmo tempo, é tarefa básica do administrador público tipo delta tentar melhorar a política. Assim, a factibilidade política deve ser aceita como um limite, mesmo que elástico, com um administrador público tipo delta dedicado à esfera de estado superior, que tenta fazer o que é necessário, ao invés de executar políticas mundanas como a arte do possível.

Para preencher tais exigências, a atividade nos partidos políticos deve ser proibida aos administradores públicos tipo delta, que devem ser desencorajados da busca do poder político; não se deve permitir que os compromissos políticos ameacem a natureza profissional do administrado público, mesmo quando estes são necessários para se identificarem com as ideologias dominantes nos países, seguindo a 'política da fé' (OAKeshott, 1996).

\subsection{Forte sentido de missão}

Com base na percepção dessas atividades, conhecidas em todo o mundo, em termos de 'chamado' e da secularização dessa concepção de Max Weber (Mommsen e Schluchter, 1992; Goldman, 1988), e também de concepções comparáveis em outras culturas, tal como expresso no The Bhagavadgita na Índia, e na cultura Samurai no Japão, minha opinião é de que ser um administrador público tipo delta deve ser considerado como um apelo vocacional, uma escolha existencial, uma missão de vida. 
Este sentido de missão deveria fornecer à vida dos administradores públicos tipo delta sentido, em termos de significado moral, recompensa interior e desafio pessoal. A não ser que essa exigência seja amplamente satisfeita, o serviço público tipo delta não será capaz de atingir os padrões necessários, apesar de todos os esforços requeridos por eles. Além disso, sem as recompensas intrínsecas e o prestígio social que acompanham uma noção tão internalizada e socialmente aceita do serviço público tipo delta, será difícil recrutar os candidatos excepcionais. A confiança pública necessária também depende do compromisso visível do servidor público tipo delta com o chamado da promoção do bem-comum.

\section{Neoplatonismo e perspectivas ativas do Estado}

O quadro que emerge das funções e atributos do serviço público tipo delta aqui proposto deveria ser claramente reconhecido como neoplatônico e ativamente baseado no Estado.

Em A República, Platão postulava um modelo puro de regulamentação onibenevolente e onipotente, inaceitável em termos das modernas concepções e valores, e impossível por várias razões, principalmente pelos efeitos corrompíveis do poder, mesmo sobre o mais virtuoso dos governantes. A outra visão extrema de Platão, em As Leis, com muito pouco escopo para intervenções humanas deliberadas, é impossível e inaceitável em uma época de mudanças hiper-rápidas.

No entanto, em $O$ Statesman, Platão apresenta a idéia de profissionais do governo que tecem o futuro com auxílio do conhecimento. É neste sentido que a administração pública tipo delta aqui proposta é neoplatônica, quando visa à introdução nos governos centrais de superprofissionais nas tarefas de maior relevância, que modelarão o futuro, como parceiros potentes, porém subordinados, dos políticos.

Desnecessário dizer que esta abordagem será o anátema das propostas da democracia populista (TÄENSJÖE, 1992; PARKER, 1994), mas ela cabe bem na teoria da democracia com qualidade como um regime misto, onde as maiorias democráticas fazem as escolhas decisivas, mas baseado na orientação sábia e iluminada pela educação, não lavagem cerebral, dos conselheiros públicos. Nada menos irá servir, considerando os desafios, oportunidades e perigos que enfrenta a humanidade como um todo e todos os países em particular.

Um segundo pressuposto para o modelo proposto de uma administração pública tipo delta é a concepção de um Estado ativo, retornando às idéias clássicas da política como arquitetura de mestre e como legislação em um sentido amplo (Collini et al., 1983). Este será o anátema para o liberalismo moderno, para alguns versos extremos de confiança em 
mercados livres e para desilusões simplistas do fim da história. Porém, não tenho dúvidas de que as funções cruciais que modelarão o futuro só podem ser preenchidas pelos governos centrais, incluindo órgãos interestatais como a União Européia e, no futuro próximo, grupos quasegovernamentais globais. A opção de enfraquecer o estado não existe, e não se pode confiar nas astúcias ocultas da história. Estados modelarão significantemente o futuro, seja para o pior, por inércia ou más escolhas, ou para o melhor, graças às capacidades drasticamente aperfeiçoadas, inter alia, com a ajuda dos administradores públicos tipo delta.

A administração pública tipo delta pode justificar-se pragmaticamente, sem explicar suas bases neoplatônicas e sua concepção ativa de Estado. No entanto, prefiro deixar o caso inteiramente nas mãos dos próprios administradores públicos tipo delta, para que eles possam resistir ao errôneo pensamento dominante sobre governança, que nada pode além de perpetuar as incapacidades do governo, com duras conseqüências. $\mathrm{O}$ redesenho radical da governança, segundo valores básicos, é uma necessidade, incluindo o movimento em favor do serviço público tipo delta.

Muitas características do serviço público tipo delta podem e devem ser ajustadas às especificidades de cada país, incluindo suas tradições, valores, recursos e instituições, à medida que se tenha o cuidado de não alterar sua essência. O movimento em direção ao serviço público tipo delta pode ser feito em fases dentro de estratégia modular, tal como um treinamento intenso dos atuais servidores públicos promissores, acompanhado da construção de um novo tipo de serviço público.

Assim, essa proposta não é utópica, mas cabe dentro dos limites do possível, se empenharmo-nos. No entanto, duas pré-condições essenciais devem ser cumpridas: a necessidade de progredir rapidamente rumo a uma administração pública tipo delta deve ser amplamente aceita nas democracias, e apoiada pelos principais detentores do poder; os líderes políticos devem estar dispostos a tomar parte ativa no movimento rumo a esse serviço, assumindo inclusive os custos intermediários envolvidos na superação da tirania do status quo, inclusive das ideologias dominantes que pregam a nova administração pública. 


\section{Referências bibliográficas}

Ball, Terence, Farr, James and Hanson, Russell L. (eds). Political Innovation and Conceptual Change. Cambridge. UK: Cambridge University Press, (1988).

Berke, Hans A.F.M., Perry, James L. and Toonher, Theo A. J. (eds). Civil Service Systems in Comparative Perspective. Bloomington: Indiana University Press, (1996). Boston, Jonathsn, Martin, John, Pallot, June, and Walsh, Pat (eds). Reshaping the State: New Zealand's Bureaucratic Revolution. Auckland: Oxford University Press, (1991).

Bovens. Mark and T. Hart, Paul, Understanding Policy Fiascoes. New Brunswick NJ: Transaction Books, (1996).

Bratman, Michael E. Intention, Plans, and Practical Reason. Cambridge, MA: Harvard University Press, (1978).

Brunsson, Nils and Olsen, Johan P. The Reforming Organization. London: Routledge, (1993).

Butler, David, Adonis, Andrew and Travers, Tony. Failure in British Government: The Politics of the Poll Tax. Oxford: Oxford University Press, (1994).

Collini, Stefan, Winch, Donald and Burrow, John. That Noble Science of Politics: A Study in Nineteenth-Century Intellectual History. Cambridge, UK: Cambridge University Press, (1983).

DE BARY, Wm Theodore. The Trouble with Confucianism. Cambridge., MA: Harvard University Press, (1991).

DroR, Yehezkel. Policymaking Under Adversity. New Brunswick, NJ: Transaction Books, (1988).

DroR, Yehezkel. Reflections of a PSO President: Policy Professionalism as a Vocational Calling. Policy Studies Journal 21 (1): 6-13, (1993).

Dror, Yehezkel. The Capacity to Govern: Report to the Club of Rome. Spanish version. Barcelona: Circulo de Lectores. 1994 and Mexico City: El Fondo de Cultura Economica, 1996. German version Ist die Erde noch regierbar? - Ein Bericht an den Club of Rome, Munich: Bertelsmann, 1995: revised English version in preparation, (1994-96).

ElSTER, Jon. Sour Grapes. Cambridge, UK. Cambridge University Press, (1983).

ElsTer, Jon. Ulysses and the Sirens, revised edn. Cambridge, UK: Cambridge University Press, (1984).

Elster, Jon. Solomonte Judgments. Cambridge, UK: Cambridge University Press, ( 1989).

ERICsson, K.A. and Smith, J. (eds). Towards a General Theory of Expertise: Prospects and Limits. Cambridge, UK: Cambridge University Press, (1991).

Goldman, Harvey. Max Weber and Thomas Mann: Calling and the Shaping of the Self. Berkeley: University of California Press, (1988).

GoRe, Al. The Gore Report on Reinventing Government-From Red Tape to Results: Creating a Government That Works Better and Costs Less. New York: Times Books, (1993).

Graham, George. Philosophy of Mind: An Introduction. Oxford: Blackwell, (1993).

GuardinI, Romano. Tugenden. 2nd edn. Mainz: Matthias-Grunewald, (1967).

Hall, David L. and Ames, Roger T. Thinking Through Confucius. Albany, NY: State University of New York Press, (1987).

Heady, Ferrel. Public Administration: A Comparative Perspective, 5th edn. New York: Marcel Dekker, (1995). 
Hirschman, Albert O. Exit, Voice, and Loyalty: Responses to Decline in Firms, Organizations, and States. Cambridge, MA: Harvard University Press, (1970).

Hirschman, Albert O. Rival Views of Market Societies and Other Recent Essays. New York: Viking, (1986).

Huddleston, Mark W. and Boyer, William W. The Higher Civil Service in the United States: Quest for Reform. Pittsburgh: Pittsburgh University Press, (1996).

JACOBS, Jane. Systems of Survival: A dialogue on the Moral Foundations of Commerce and Politics. New York: Random House, (1992).

KaPlan, Mark. Decision Theory and Philosophy. Cambridge, UK: Cambridge University Press, (1996).

Kaufmann, Franz-Xaver (ed.). The Public Sector: Challenge for Coordination and Learning. Berlin: Walter de Gruyter, (1991).

KeNNEDY, Paul. Preparing for the Twenty-First Century. New York: Random House, (1993)

KING, Alexander and SCHNEIDER, Bertram. The First Global Revolution: A Report by the Council of the Club of Rome. London: Simon and Schuster, (1991).

KIRDAR, Üner (ed.) Change: Threat or Opportunity? Five Volumes. New York: United Nations Development Programme, (1992).

KIRDAR, Üner and Silk, Leonard (eds). A world Fit for People. New York: New York University Press, (1994).

Knoblock, John. Xunzi: A Translation and Study of the Complete Works. Volume II: Books 7-16. Stanford, CA: Stanford University Press, (1990).

KöNIG, Klaus. Zur Kritik Eines Neuen Offentlichen Managements. Speyer: Forschungsinstitute Für Öffentliche Verwaltung bei der Hochschule für Verwaltunswissenchaften Speyer, (1995).

KupPerman, Joel J. Character. Oxford: Oxford University Press, (1991).

MacDonagh, Oliver. The Nineteenth Century Revolution in Government: A Reappraisal, Historical Journal I (1): 52-67, (1958).

MacInTYRe, Alasdair. After Virtue, 2nd edn. Notre Dame, IL: University of Notre Dame Press, (1984).

McDonald, Oonagh. The Future of Whitehall. London: Weidenfeld and Nicolson.

Merritt, Richard L. and Merritt, Anna J. (eds). Innovation in the Public Sector. Beverly Hills, CA: Sage, (1992).

Mitroff, Ian, Mason, Richard O. and BarabBa, Vincent P. "Beyond Contradictions and Consistency: A Design for a Dialectic Policy System". Theory and Decision 15 (Jun.): 107-20, (1983).

Mommsen, Wolfgang J. and Schluchter Wolfgang (eds). Wissenschaft als Beruf/Politik als Beruf, Max Weber Gesamtausgabe. Volume 17. Tübingen: JCB Mohr, (1992).

Moore, Mark H. Creating Public Value: Strategic Management in Government. Cambridge, MA: Harvard University Press, (1995).

North, Douglass C. Institutions, Institutional Change and Economic Performance. Cambridge, UK: Cambridge University Press, (1990).

Nussbaum, Martha C. Love's Knowledge: Essays on Philosophy and Literature. New York: Oxford University Press, (1990).

Nussbaum, Martha C. Poetic Justice: The Leterary Imagination and Public Life. Boston, MA: Beacon Press, (1995).

OAKEshott, Michael. The Politics of Faith and the Politics of Scepticism. New Haven, CT: Yale University Press, (1996).

OECD. Governance in Transition. Paris: OECD/PUMA, (1995).

Osborne, David and Gaebler, Ted. Reinventing Government. Reading, MA: Addison-Wesley, (1992). 
Parker, D. Richard. "Here, the People Rule": A Constitutional Populist Manifesto. Cambridge, MA: Harvard University Press, (1994).

Paulos, John Allen Innumeracy: Mathematical Illiteracy and its Consequences. New York: Hill and Wang, (1988).

SCHAefer, F. Guenther and McInemey, Eamon (eds). Strengthening Innovativeness in Public Sector Management. Maastricht: European Institute of Public Administration.

SCHUMPETER, Joseph A. (1942). Capitalism, Socialism and Democracy. New York: Harper and Row, (1988).

Schon, D.A. The Reflective Practitioner: How Professionals Think in Action. New York: Basic Books, (1983).

Senge, Peter M. The Fifth Discipline: The Art and Practice of The Learning Organization. New York: Doubleday, (1990).

Sigma. Top Management Service in Central Government: Introducing a System for the Higher Civil Service in Central and Eastern European Countries. Paris: OECD, (1995).

Silberman, Bernard S. Cages of Reason: The Rise of the Rational State in France, Japan, the United States and Great Britain. Chicago, IL: University of Chicago Press, (1993).

STERnBERG, Robert J. and WAGner, Richard K. (eds). Practical Intelligence: Nature and Origins of Competence in the Everyday World. Cambridge, UK: Cambridge University Press, (1986).

TÄENnSJÖE, Torbjöern. Populist Democracy: A Defence. London: Routledge, (1992).

Thagard, Paul (1992). Conceptual Revolutions. Princeton, NJ: Princeton University Press.

Thomas, Rosamund M. (ed). Teaching Ethics - Volume One: Government Ethics. Cambridge, UK: Centre for Business and Public Sector Ethics, (1993).

WaLEY, Arthur. The Analects of Confucius. London: Unwin Hyman, (1988).

Wallace, James D. Virtues and Vices. Ithaca, NY: Cornell University Press, (1978).

Wamsley, Gary L. et al. Refounding Public Administration. Newbury Park, CA: Sage, (1990)

Wildavsky, Aaron. Speaking Truth to Power: The Art and Craft of Policy Analysis. London: Macmillan, (1979).

Williams, Bernard et al. (1985). Politics, Ethics and Public Service. London: Royal Institute of Public Administration.

WiLLIAmson, Oliver E. The Mechanisms of Governance. Oxford: Oxford University Press, (1996).

Wright, Arthur F. and Twitchett, Denis (eds). Confucian Personalities. Stamford, CT: Stamford University Press, (1992). 


\section{O administrador público tipo delta para o século 21 Yehezkel Dror}

$\mathrm{O}$ artigo estuda um aspecto da reforma do Estado que, segundo o autor, tem sido sistematicamente negligenciado pelas atuais propostas que focalizam o modelo da administração gerencial. Trata-se das funções vitais do governo de tomar decisões críticas e adotar políticas diante das mudanças provocadas pela revolução global. Segundo Dror, as tarefas de alto comando (high-order tasks) de definir trajetórias e as novas formas de governança exigem um ajuste significativo do governo central. Este ajuste refere-se, principalmente, à concepção e ao desenvolvimento de um novo padrão de funcionários do primeiro escalão público, o qual contribuiria com conhecimento e perspectivas para enfrentar as tarefas de alto comando.

O autor estabelece uma tipologia para caraterizar a evolução do perfil do serviço público, marcando suas fases históricas: a) tipo alpha (status atribuído, fusão de papéis políticos e administrativos); b) tipo beta (compra de cargos governamentais) e c) tipo gamma (quase profissionalismo). O novo funcionário sênior, do tipo delta, se concentraria nas questões de ordem estratégica, deixando as funções gerenciais para servidores do tipo gamma e para os serviços técnicos.

Após uma breve análise, Dror conclui que o funcionalismo público de primeiro escalão, na maioria dos países (com exceção de alguns países do Sudeste Asiático), encontra-se obsoleto, com base profissional inadequada e capacidade insuficiente para lidar com escolhas críticas.

\section{El administrador público tipo delta para el siglo 21 Yehezkel Dror}

El artículo estudia un aspecto de la reforma del Estado que, según el autor, ha sido sistematicamente negligenciado por las actuales propuestas que enfocan el modelo de la administración gerencial. Se trata de las funciones vitales del gobierno de tomar decisiones críticas y adoptar políticas delante de los cambios provocados por la revolución global. Según Dror, las tareas de alto comando (high-order tasks) de definir trayectorias y las nuevas formas de governanza exigen un ajuste significativo del gobierno central. Este ajuste se refiere, principalmente, a la concepción y al desarollo de un nuevo padrón de funcionarios de primera jerarquía, lo que contribuiria con conocimiento y perspectivas para afrontar las tareas de alto comando.

El autor establece una tipologia para caracterizar la evolución del perfil del servicio público, marcando sus fases historicas: a) tipo alpha: (status atribuido, fusión de papeles políticos y administrativos); b) tipo beta: (compra de cargos gubernamentales) y c) tipo gamma: (casi profesionalismo). El nuevo funcionario senior, del tipo delta, se concentraria en las cuestiones de orden estratégica, quedándose las funciones gerenciales para los servidores del tipo gamma y para los servicios técnicos.

Tras un breve análisis, Dror concluye que el funcionarismo público de primera jerarquía, en la mayoria de los países (excepto algunos países del Sudeste Asiático), se encuentra obsoleto, con bases professionales inadecuadas y capacidad insuficiente para lidar con opciones críticas.
Revista do

Serviço

Público

Ano 48

Número 2

Mai-Ago 1997

Yehezkel Dror

é professor emérito de ciência política e professor catedrático de administração pública da Hebrew University of Jerusalem, Israel 
Delta-type senior civil service for the $21^{\text {st }}$ century

Yehezkel Dror

The article alludes to one aspect of the State reform that, according to the author, has been systematically neglected by present proposals focused on the management administration model. Government's vital functions are to make critical decisions and to adopt policies when facing changes brought about by the global revolution. According to Dror, the high-order tasks of defining trajectories and new forms of governance demand a significant adjustment of central governments. This adjustment refers mainly to the creation and development of a new profile of senior civil servants, who would present their contribution to high-order tasks with more knowledge and perspective.

The author establishes a categorization to illustrate the evolution of the civil servant profile, highlighting its historical phases: a) alpha type (attributed status, fusion of political and administrative roles); b) beta type (purchase of governmental positions); and c) gamma type (quasi-professionalism). The new delta-type senior civil servant should concentrate on strategical issues, leaving managerial functions to gamma-type civil servants and to technical services.

After a brief analysis, Dror declares that the senior civil service in most countries (exceptions to be made to some East-Asian countries) is obsolete, lacking adequate professional basis and capacity to deal with critical decisions. 